\title{
Potential use of a novel telemetric sensor capsule in patients with suspected gastrointestinal bleeding during the COVID-19 pandemic
}

Upper gastrointestinal endoscopy during the COVID-19 pandemic carries a risk of disease transmission [1,2]. The HemoPill (Ovesco Endoscopy, Tübingen, Germany) is composed of an orally administered telemetric sensor capsule that is capable of detecting blood and hematin, and a wireless receiver for data display [3-5]. Results are expressed as the HemoPill indicator $(\mathrm{HI})$. A HI value $\geq 0.8$ during the first 10 minutes of the examination or $\geq 1.0$ thereafter denotes a positive test result. We evaluated this sensor capsule in patients with confirmed or suspected COVID-19.

Case \#1 was a patient with COVID-19, congestive heart failure, and severe obesity who reported melena and had a drop of hemoglobin from $14.6 \mathrm{~g} / \mathrm{dL}$ to $11.3 \mathrm{~g} /$ $\mathrm{dL}$. She required low-flow oxygen but was otherwise clinically stable. The maximum $\mathrm{HI}$ value was 1.0 after 89 minutes ( $\triangleright$ Fig.1a). Endoscopy subsequently showed a gastric ulcer with a non-bleeding visible vessel ( $\triangleright$ Fig. 1 b).

Patient \#2 suffered from dyspnea and anemia (hemoglobin $4.3 \mathrm{~g} / \mathrm{dL}$ ) with possible gastrointestinal bleeding. She was routinely tested for SARS-CoV-2 and isolated until receipt of her result. The

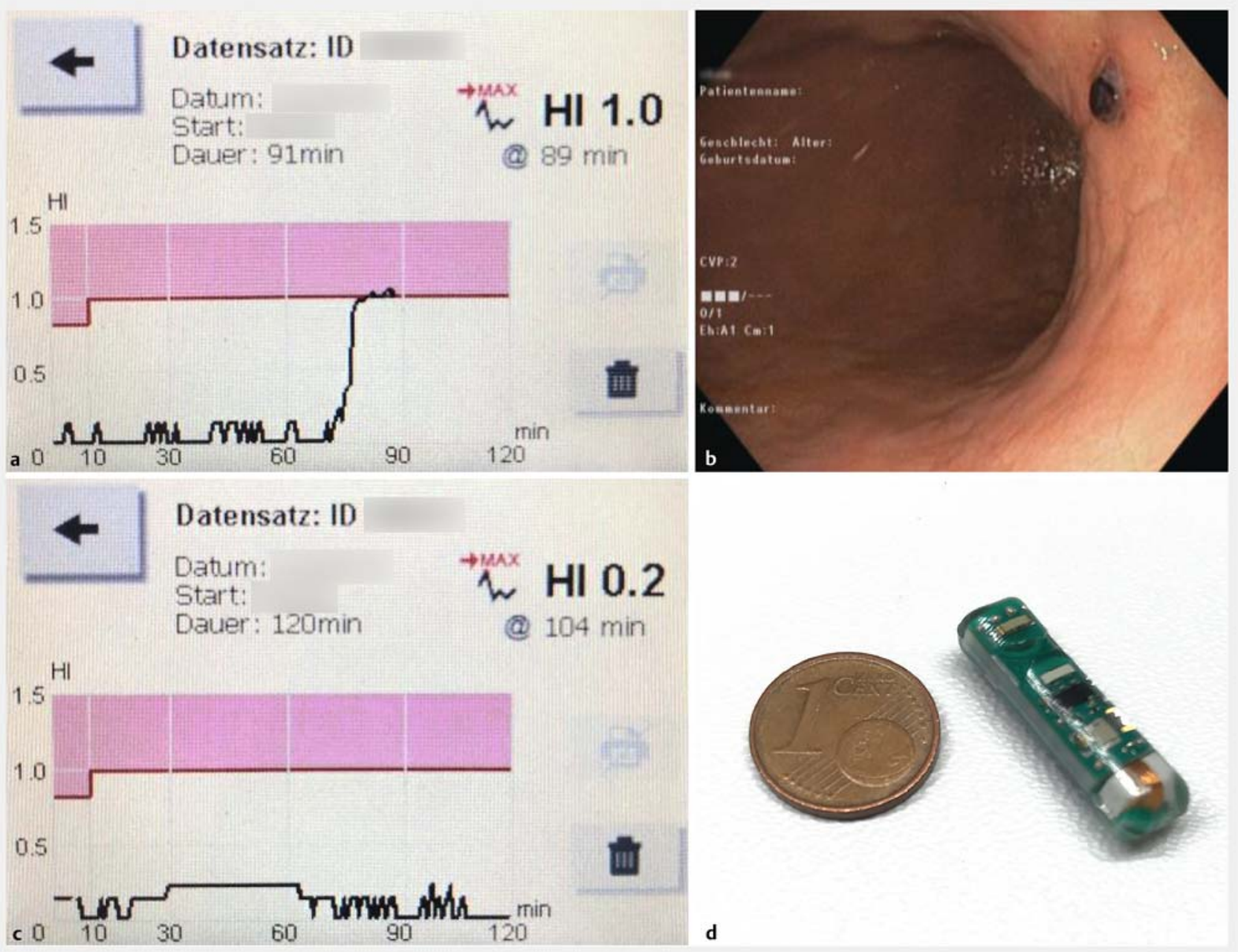

- Fig. 1 Images of HemoPill examination in two patients showing: a a screenshot of the HemoPill Receiver in patient \#1, which revealed a maximum $\mathrm{HI}$ of 1.0 after 89 minutes of examination, therefore denoting a positive test result; $\mathbf{b}$ endoscopic image in patient \#1, with a nonspurting visible vessel identified in the stomach that was treated with through-the-scope clips; $\mathbf{c}$ a screenshot of the HemoPill Receiver in patient \#2, which revealed a negative test result; $\mathbf{d}$ a photograph of the HemoPill capsule, an orally administered telemetric sensor capsule capable of detecting liquid blood or hematin. 
maximum $\mathrm{HI}$ value was 0.2 ( $>$ Fig.1c). Her endoscopy, which showed no evidence of gastrointestinal bleeding, was postponed for 48 hours until receipt of negative test result.

Patient \#3 suffered from COVID-19 and was therefore receiving anticoagulant therapy. He underwent endoscopic retrograde cholangioscopy with papillotomy because of biliary pancreatitis; he reported a single episode of hematochezia 1 week after the endoscopy and his hemoglobin had dropped by $4.5 \mathrm{~g} / \mathrm{dL}$ to $7.9 \mathrm{~g} / \mathrm{dL}$. His maximum $\mathrm{HI}$ value was 0.8 and no endoscopy was performed. No further episodes of bleeding were reported and the patient's hemoglobin remained stable.

This sensor capsule ( $\triangleright$ Fig. 1 d) might aid in decision-making during the COVID-19 pandemic. In patients with as yet unavailable COVID-19 test results, it might aid in determining the appropriate timepoint for endoscopy. In patients who are positive for COVID-19 with suspected gastrointestinal bleeding, it could help in deciding whether to perform an endoscopy or not and thereby potentially help minimizing risk of disease transmission.

\section{Competing interests}

The Department of Internal Medicine I, Hospital Ludwigsburg receives funding from Ovesco Endoscopy AG to conduct different prospective trials. B. Meier was funded by Ovesco Endoscopy for research activities. K. Caca recieved grants and speecher fees from Ovesco Endoscopy. The other authors declare that they have no further conflict of interest.

The authors

Ismaeil Elsayed, Benjamin Meier, Karel Caca, Andreas Wannhoff

Department of Internal Medicine I, Hospital

Ludwigsburg, Ludwigsburg, Germany

\section{Corresponding author}

\section{Karel Caca, MD}

Department of Internal Medicine I, Hospital Ludwigsburg, Posilipostrasse 4, 71640

Ludwigsburg, Germany

Karel.Caca@rkh-kliniken.de

\section{References}

[1] Wölfel R, Corman VM, Guggemos W et al. Virological assessment of hospitalized patients with COVID-2019. Nature 2020; 581 : 465-469
[2] Gralnek IM, Hassan C, Beilenhoff U et al. ESGE and ESGENA Position Statement on gastrointestinal endoscopy and the COVID19 pandemic. Endoscopy 2020; 52: 483490

[3] Schmidt A, Zimmermann M, Bauder M et al. Novel telemetric sensor capsule for EGD urgency triage: a feasibility study. Endosc Int Open 2019; 7: E774-E781

[4] Schostek S, Zimmermann M, Keller J et al. Pre-clinical study on a telemetric gastric sensor for recognition of acute upper gastrointestinal bleeding: the "HemoPill monitor". Surg Endosc 2020; 34: 888-898

[5] Schostek S, Zimmermann M, Keller J et al. Volunteer case series of a new telemetric sensor for blood detection in the upper gastrointestinal tract: The HemoPill. Dig Dis Sci 2016; 61: 2956-2962

Bibliography

Endoscopy 2021; 53: 337-338

DOI 10.1055/a-1319-1496

ISSN 0013-726X

published online 13.1.2021

(c) 2021. Thieme. All rights reserved.

(c) Georg Thieme Verlag KG Stuttgart · New York 